\title{
Water Absorbing Plantation Clay for Vertical Greenery System
}

\author{
Lih-Jiun $\mathrm{Yu}^{1}$, Aegil De Vera Santos ${ }^{1}$, Khang-Wei $\operatorname{Tan}^{1}$ and Mou'ad A Tawawneh ${ }^{2}$ \\ ${ }^{1}$ Faculty of Engineering, Technology and Built Environment, UCSI University, Kula Lumpur Campus (North Wing, Lot 12734, Jalan Choo \\ Lip Kung, Taman Tayton View, 56000 Cheras, Kuala Lumpur, Malaysia. \\ ${ }^{2}$ Department of Physics, College of Science, Al-Hussein Bin Talal University, Ma'an, P.O Box 20, Jordan.
}

\begin{abstract}
With the arises of environmental conscious, the usage of vertical garden system has become more popular in urban cities. Citizens can enjoys the benefits of energy and cost saving besides ornamental effect. More investigations have been conducted on green facades led to the cities ecological enhancement.However, limited plants species can be planted for green facades systems as this system does not provide sufficient soil and nutrients for common plants. Alternative plantation methods such as planted box and felt system required additional maintenance attention. The idea of using clay composite which consists of nutritious soil, water absorbing polymer and flexible cement clay potentially become alternative vertical greenery systems that offers economic and sustainable plantation platform for more variety of plants.The fabricating of clay composite involved three processes, they are: mixing, moulding and drying. Physical properties characterisation (density, $\mathrm{pH}$, compression test, aging test and water immersion test) were tested on the dried fabricated clay composite to ensure their sustainability in tropical climate. The results showed that clay composite with $1.5 \mathrm{wt} \%$ of cement and $0.3 \mathrm{wt} \%$ superabsorbent polymer shows optimum water absorbing properties. This system are expected to enable more agriculture activities in urban living.
\end{abstract}

\section{Introduction}

Using plants and greenery is an ecological solution to reduce ambient temperatures, mitigation of urban heat island effect and building energy saving [1]. Plants on vertical landscaping absorb dust and clean air, and in this way they work as natural air filtration [2,3]. Moreover, the use of plants offers natural advantages as plants are clean source and it has the ability to control noise and use as barriers for noise abeyance [4]. The development in vertical greenery system is emerging, as a results of limited green area in developing cities and growing of environmental consious. In some area, installment of vertical greeney system are receiving encouragement from authorities. For example, the German Jugendstil movement (Art Nouveau) from the early 20th century encouraged the integration of the house with the garden and emerged some incentive programs for the installation of green facades [5].

However, there are potential problems associated with linking the building with living organism. A supportive structures together with well designed dranaige system are essential to enable the sustainability of plant growth which variable along the time and space as the plants grows. Moreover, vegetation is usually linked to drawbacks such as higher initial investment, maintenance costs, and possible damages to the building [6]. Furthermore, the challenge when using growing media for vertical greenery systems is larger as the vertical orientation of the growing media increases the risks of uneven distribution of water and air, making the gravitational important [7]. The conventional vertical garden system by using green facaedes are limited to application of climbing plants species along the wall. In contrast, the living wall system, especially modular living wall system, is getting more popular in urban cities application. This system consists of growing media where it is supported by complementary structure, such as: planted box or felt system, allows uniform growth of light weight plants along the vertical wall. However, these systems required varies of investment cost and additional maintanance attention, subjected to the types of system employed [6].

A good growing media is one of the key aspects in constructing vertical greenery systems. They must be able to maintain moisture, firm, allow good aeration, free from pests, low salinity, enable high cation exchange capacity for nutrients, consistent in quality and economic available. The postivie effect of superabsorbent polymer (or known as hydrogels) application as soil additives for the retention of water in soil has been reported widely [8-10]. The optimum superabosorbent polymer usage for plant growth is $0.3 \%$ [9].

Developing a successful system for vertical greenery systems requires solid knowledge of the properties of the growing media. Hence, selecting a proper growing media is one of the key factors in building vertical greenery systems. The idea of using clay composite which consists of nutritious soil, water absorbing polymer and flexible cement clay potentially become alternative vertical 
greenery systems that offers economic and sustainable plantation platform for more variety of plants. The combination of superabsorbent polymer with plantation clay composites are expected to beneficial from low mainatenance needs in the aspects of reducing irrigation frequency and pipes replacement frequency. Cement is a potential material that readily available, low cost yet effective to enhance viscidity is being considered as growing media. However, the control of cement content is crucial as the plant growth and flower colors are affected by the alkalinity of the soil resulting from alkaline agent application $[11,12]$. Thus, the balancing of cost efficiency with the sustainability of plant growth becomes challenging.

In this paper, we study the effect of cement content in clay composite on water absorbing properties. The sustainability of plants growth in the clay composite were investigated.

\section{Methodology}

\subsection{Materials}

Malaysia plantation grade clayed soil, black soil and superabsorbent polymer (sodium polyacrylate) were supplied by SJH Nursery \& Landscaping Sdn. Bhd. Ordinary portland cement were supplied by Lafarge, Malaysia.

\subsection{Sample preparation}

The clay composites of different composition were mixed according to the ratio as in Table 1 . The soil mixtures were maintained at 1:4 of black soil: clayey soil respectively. The clay mixtures were added with $50 \mathrm{ml}$ of water and moulded into the mould with dimension $13 \mathrm{~cm}$ x $13 \mathrm{~cm}$ x $12 \mathrm{~cm}$ (length $\mathrm{x}$ width $\mathrm{x}$ height), leaving a hollow space of $2 \mathrm{~cm}$ diameter in the center for plantation. Then, the mixtures were compressed, allowed for cure and dry naturally under sunlight for three days.

Table 1. Mixing composition of clay composite.

\begin{tabular}{|c|c|c|c|}
\hline \multirow{2}{*}{ Sample } & \multicolumn{3}{|c|}{ Composition (wt\%) } \\
\cline { 2 - 4 } & $\begin{array}{c}\text { Soil } \\
\text { mixture } \\
\text { (Black soil } \\
\text { \& Clayey } \\
\text { soil) }\end{array}$ & $\begin{array}{c}\text { Superabsorbent } \\
\text { polymer } \\
\text { (Sodium } \\
\text { polyacrylate) }\end{array}$ & Cement \\
\hline A & 100 & 0 & 0 \\
\hline B & 98.3 & 0.30 & 1.5 \\
\hline C & 96.7 & 0.30 & 3.0 \\
\hline D & 95.2 & 0.30 & 4.5 \\
\hline
\end{tabular}

\subsection{Characterization}

Physcical tests such as: $\mathrm{pH}$ test, water absorbing test, density, compression test, water immersion test were conducted to ensure the clay composite materials are able to sustain in tropical climate before starts planting the plants. Water absorbing test was performed by using tea-bag method [13]. The chosen plant species for plantation was Cuphea hyssopifolia (Mexican Heather). Then, plant sustainability was evaluated based on plant's growth length with controlled irrigation (100 ml per day) and ultraviolet rays $\left(1350 \mathrm{~W} / \mathrm{m}^{2}, 10\right.$ hours).

\section{Results and discussion}

\subsection{Density}

The densities of raw material for clay composite are listed in Table 2. The theoretical density of clay composites with various cement content was calculated based on weight percent of composition as listed in Table 1. The actual density of all samples was measured by Archimedes principles were compared with theoretical density in Figure 1. From Figure 1, it is clearly shown that the actual densities of clay composite are lower than the theoretical densities. Lower densities of clay composite could be attributed to the larger volume appear in all samples due to high porosity and the air trapped in samples during sample preparation. It was found that the sample A (without cement) appear to have lower density due to absence of cement to bind the materials in to close pack arrangement. Some loose soil particles were separated easily from the bulk sample.

Table 2. Density of dry materials.

\begin{tabular}{|c|c|}
\hline Sample & Density $\left(\mathbf{g} / \mathbf{c m}^{3}\right)$ \\
\hline Clayey & 1.32 \\
\hline Black soil & 1.41 \\
\hline Sodium polyacylate & 1.23 \\
\hline Cement & 3.15 \\
\hline
\end{tabular}

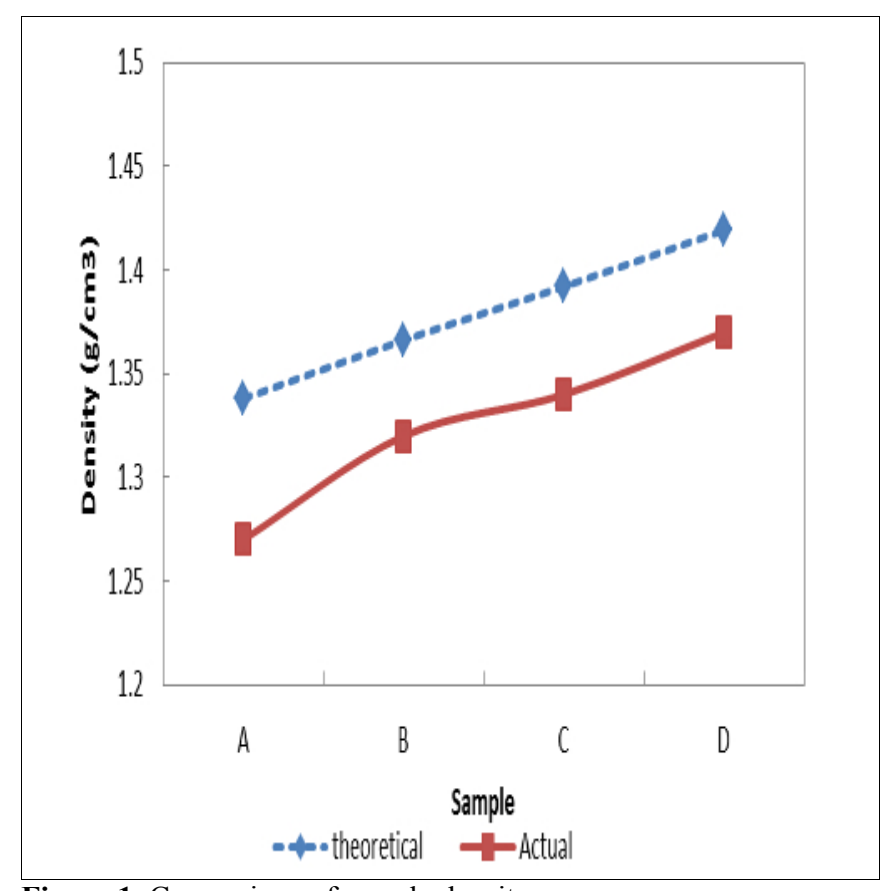

Figure 1. Comparison of sample density. 


\section{$3.2 \mathrm{pH}$}

Table 3 showed $\mathrm{pH}$ values of all samples. It was observed that an increment of cement content in the samples contributing to the increment of $\mathrm{pH}$ values. The $\mathrm{pH}$ of damp soil mixture without the presence of cement is almost similar to the $\mathrm{pH}$ of tap water in the range of 7.57.8. The presence of cement content from $1.5-4.5 \%$ was increasing $\mathrm{pH}$ upto 11.5. This results are in line with [14] in which showed that $\mathrm{pH}$ in original soil was increased from 9.5 to 11.0 when the cement content is between 1.0 to $2.0 \%$. The optimum cement content for the synthetic soils in rock slope application was reported at 1.5\% cement [9]. Based on the results in Table 3, the $\mathrm{pH}$ values of clay composites degrade as time extends. The degradation of $\mathrm{pH}$ values are attributed to carbonation process. Calcium hydroxide, which contains in the cement, reacts with carbon dioxide to form calcium carbonate and water. This process is naturally diluting the alkalinity of the clay composite from $\mathrm{pH} 11$ to $\mathrm{pH} 8$ in three weeks. These changes are favorable for plants growth as the clay composite condition became close to neutral.

Table 3. $\mathrm{pH}$ values of samples.

\begin{tabular}{|c|c|c|c|c|}
\hline & \multicolumn{4}{|c|}{ pH } \\
\hline Sample & Week 1 & Week 2 & Week 3 & Week 4 \\
\hline Water & 7.5 & - & - & - \\
\hline A & 7.8 & 7.7 & 7.6 & 7.6 \\
\hline B & 11.3 & 10.8 & 7.9 & 7.9 \\
\hline C & 11.3 & 11.1 & 8.1 & 8.0 \\
\hline D & 11.5 & 11.1 & 8.0 & 7.9 \\
\hline
\end{tabular}

\subsection{Water absorbing properties and compress stress test}

Figure 2 showed water absorbed by clay composite and maximum compression stress experienced by clay composite before failure occurs. Line chart indicates water absorbed per gram of dry samples. Water absorbed by soil mixtures (sample A) is $0.46 \mathrm{ml}$ per mass of dry soil. The amount of water absorbed in sample B after introducing cement and superabsorbent polymer almost 1.8 folds of samples A. The hydrophilic functional chains in superabsorbent polymer can hold a large amount of water and swell. The cross-linked chains in superabsorbent polymers tends to maintain their physical dimensional structure [15]. The postivie effect of superabsorbent polymer application as soil additives for the retention of water in soil are consistent with $[8-10,16]$ However, further increment of cement content after 1.5 $\mathrm{wt} \%$ led to decreasing water absorbing properties. Water permeability of cement is reduced after cured, thus improving water resistance [17]. The presence of higher cement content in the clay composite led to a barrier effect and restricted water absorbs into the soil and water absorbent polymers. Hence, reducing the water absorbing capacity of the clay composite.

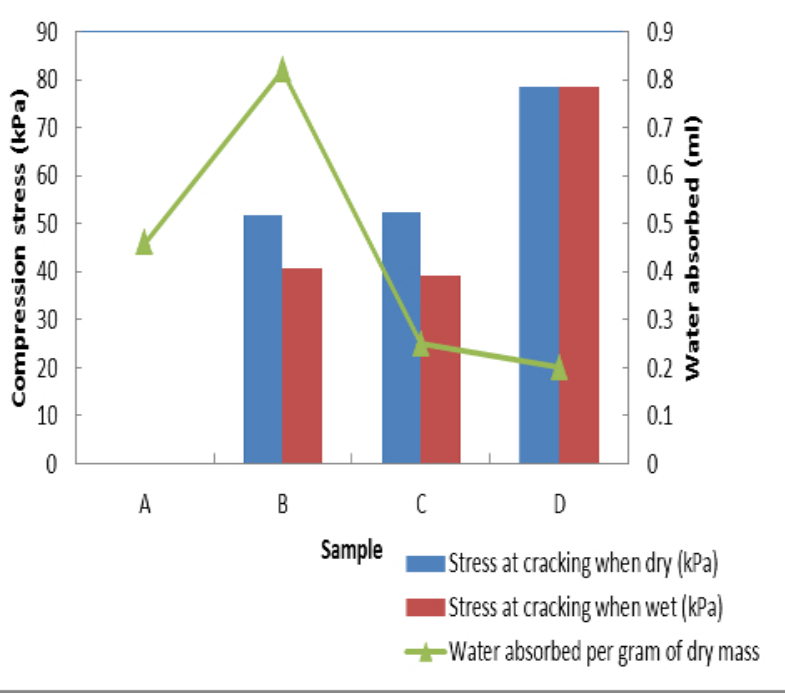

Figure 2. Water absorbed by clay composite and maximum compression stress experienced by clay composite before failed.

The benefits of cement enhancing soil through increasing soil strength, durability, rigidity and decreasing the soil permeability and deformability $[11,18$, 19]. Bar chart in Figure 2 shows maximum compression stress applied on the clay composite before crack exists. It was found that the data is invalid for sample A, because compacted soil mixtures are prone to compression test either in dry or wet condition. With the addition of cement, the clay composites showed improvement in resisting the material failure upon apply compression stress. Cracks are visible on the applied clay composite surface around $52 \mathrm{kPa}$ (under dry condition) and $40 \mathrm{kPa}$ (under wet condition) for both sample B and C. While sample $\mathrm{C}$ with highest cement content $(3 \mathrm{wt} \%)$ showed highest compression stress resistance at $78.4 \mathrm{kPa}$ for both wet and dry condition. The presence of surface imperfection on the clay composite surface serves as water duct. They feed the crack surface and damage the interface with water for further migration into the material by capillary suction [20]. Hence brittle fracture was accelerating under damp condition.

\subsection{Plant growth}

Figure 3 shows Cuphea hyssopifolia (Mexican Heather) plant's height planted in different clay composites. All plants are able to survive and continue to grow with fixed amount irrigation per day. Sample A shows highest average grow rate with $0.82 \mathrm{~cm} /$ week. Meanwhile, the average growth rates of plants are around 0.56 to 0.66 $\mathrm{cm} /$ week for all samples with of cement. The plants growth rates are dependent on the plant species. For some plants which are favor to grow in acidic environment, the present of heavy metals in cement may disturb metabolic process of plants [21]. Slower grow rate of Cuphea hyssopifolia plant could be attributed to the alkalinity environment resulting from cement. This revealed that cement has negative impact towards Cuphea hyssopifolia plant growth regardless to the water absorbing properties 
of the growing media. It was observed that the Cuphea hyssopifolia plant average growth rate for all samples were increased $(0.53$ to $0.96 \mathrm{~cm} /$ week) after three weeks. Growth rate of plant was inclined, when the $\mathrm{pH}$ of clay composites reduced to $\mathrm{pH}$ of range 7.6 to 8.1 . In conclusion, the plants growth rate is retarded by high alkalinity environment. On the contrary, the plants grow more rapidly at neutral environment.

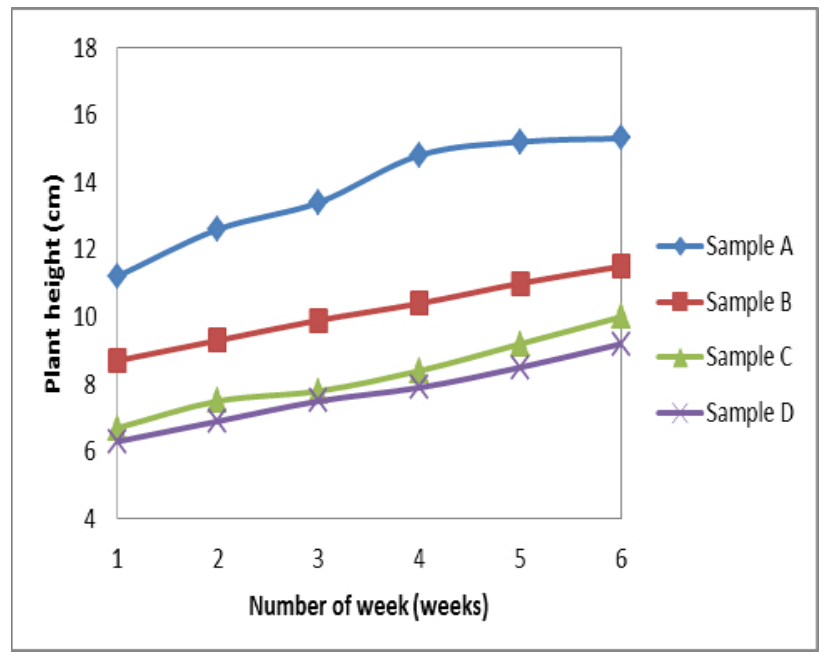

Figure 3. Plant's growth in different clay composites.

\section{Conclusion}

Clay composite samples were prepared by mixing of soil mixture and superabsorbent polymer at different cement concentration. Incremental of higher cement percentage in clay composites improved compression stress for both dry and damp condition. The plant's growth rate is increased when natural degradation of $\mathrm{pH}$ occurred after three weeks. The results showed that the system consists of nutritious soil, $0.3 \mathrm{wt} \%$ water absorbing polymer and $1.5 \mathrm{wt} \%$ of flexible cement clay is potentially offers economic and sustainable plantation platform. Further works are needed to investigate the clay composite's water retention properties, impact of weather on the clay composites and the sustainability of different plants species.

\section{References}

1. G. Perez, J. Coma, I. Martorell, L.F. Cabeza, Renew. Sust. Energ. Rev. 39, 139 (2014)

2. P. Sunakom, C. Yimprayoon, Procedia Eng. 21, 34 (2011)

3. T. Safikhani, A. Abdullah, D.Ossen, N. Baharvand, Renew. Sust. Energ. Rev. 40, 450 (2014)

4. N.H. Wong, T.A.Y. Kwang, P.Y. Tan, K. Chiang, N.C. Wong, Build Environ. 45, 411 (2010)

5. M. Manso, J.Gomes, Renew. Sust. Energ. Rev. 41, 863 (2014)

6. K. Perini, P. Rosassco, Build Environ. 70, 110 (2013)

7. S. Sonmez, D. Buyuktas, F. Okturen, S. Citak, Geoderma 144, 361 (2008)
8. X. Li, J-Z. He, J.M. Hughes, Y-R. Liu, Y-M. G-J. Gao, J.G. Yuan, R.H. Han, G-R. Xin, Z.Y. Yang, Ecol. Eng. 30, 303 (2007)

9. Zheng, Appl. Soil Ecol. 72, 58-63 (2014)

10. L. Yang, Y. Yang, Z. Chen, C. Guo, S. Li, Ecol. Eng. 62, 27 (2014)

11. E.A. Basha, R. Hashim, H.B. Mahmuf, A.S. Muntojar, Constr. Build. Mater. 19, 448 (2005)

12. D. Zhao, Z. Hao, J. Wang, J. Tao, Sci. Hortic. 154, 45 (2013)

13. M.J. Zohuriaan-Mehr, K. KAbiri, Iran. Polym. J. 17(6), 451 (2008)

14. A.K. Bin, T. Ahmad, T. Bin, R. Mohd, A.L. Bin, In. Geoenviron. Eng: Integrated Management of Groundwater and Contaminated Land-Fourth Br. Geotech. Assoc. Conf, 477 (2005)

15. F.L. Buchholz, A.T, Graham, Modern Superabsorbent Polymer Technology, (1997)

16. F. Yazdani, I. Allahdadi, G.A. Akbari, Pak. J. Biol. Sci. 10(23), 4190 (2007)

17. P. Halamickova, R.J. Detwiler, D.P. Bentz, E.J. Garboczi, Cem. Concr. Res. 25(4), 790 (1995)

18. C.A. Anagnostopoulos, Tunn. Underfr. Sp. Tech. 20, 525 (2005)

19. P.J. Walker, Cem. Concr. Comp. 17, 301 (1995)

20. P. Zhang, F.H. Wittmann, T.J. Zhao, E. Lehmann, P. Vontobel, S. Hartmann, Restor. Build. Monuments. 15(2), 91 (2009)

21. M.Z.Iqbal, M. Shafig, Turk. J. Bot. 25, 19 (2001) 